\title{
MEMBANGUN KARAKTER PENDIDIKAN PERSPEKTIF PENDIDIK DAN TENAGA KEPENDIDIKAN DALAM BUDAYA MASYARAKAT BANJAR
}

\author{
Kamrani Buseri*
}

\begin{abstract}
ABSTRAC'T
Tulisan ini bermaksud melakukan eksplorasi terhadap upaya membangun karakter pendidikan perspektif pendidik dan tenaga kependidikan dalam budaya masyarakat Banjar. Para ulama, tuan guru, guru, ustaz dan lainnya berperan dalam mengembangkan pola pendidikan sepanjang sejarah masyarakat Banjar. Bangunan karakteristik pendidikan yang terus menerus selalu ada sepanjang sejarah ialah pendidikan keislaman, mengingat Islam merupakan identitas masyarakat Banjar. Penyesuaian dengan tuntutan keadaan selalu menjadi kebijakan pendidikan masyarakat Banjar. Hal tersebut diperkuat oleh banyaknya ulama yang berlatar belakang pendidikan luar negeri yang sangat mempengaruhi modernitas pendidikan di masyarakat Banjar. Sesuai sejarah perkembangan awal masyarakat Banjar, ulama sebagai pendidik sekaligus sebagai juru dakwah merupakan kompetensi ganda bagi pendidik yang seharusnya menjadi karakter pendidik hingga saat ini. Lembaga pendidikan selain misi mendidik juga misi dakwah. Pada situasi tertentu pendidik juga dibenarkan terjun ke dunia politik dengan tujuan utama memperkuat pendidikan masyarakat dan bangsa.
\end{abstract}

Kata kunci: karakter pendidikan, pendidik, tenaga kependidikan, budaya Banjar

\section{Pendahuluan}

Pendidikan tidak pernah keluar dari budaya, karena salah satu fungsi pendidikan selain transper pengetahuan dan keterampilan juga tranper nilainilai budaya yang ada di masyarakat. Bahkan pendidikan bisa berfungsi sebagai transpormasi budaya yakni perubahan dan pengembangan budaya. Juga bisa berfungsi sebagai pelestari budaya.

*Guru Besar Ilmu Pendidikan Islam, pengajar Ilmu Pendidikan Islam, Filsafat Ilmu dan Manajemen Pendidikan Islam pada Pascasarjana IAIN Antasari, Ketua Dewan Pengawas Syariah Bank Kalimantan Selatan, Asesor Badan Akreditasi Nasional Perguruan Tinggi (BAN PT), dan Ketua Dewan Penasehat MUI Kalimantan Selatan. 
Budaya yang merupakan hasil cipta, rasa dan karsa manusia bisa berbentuk pisik material dan bisa berbentuk spiritual. Oleh sebab itu kita mengenal budaya material dan budaya spiritual. Sementara esensi budaya adalah nilai-nilai yakni sesuatu yang dianggap berharga oleh manusia dan masyarakatnya. Nilai-nilai tersebut tidak terlepas dari keyakinan yang dianut mereka. Masyarakat Banjar yang memiliki karakteristik muslim, maka dengan meyakini terhadap Islam sebagai ajaran, akan banyak mempengaruhi nilai-nilai yang dihargai mereka, dan tentu saja berpengaruh terhadap budaya mereka.

Dalam perkembangan masyarakat dan budayanya tidak bisa dipisahkan dengan pendidikan yang eksis di tengah-tengah masyarakat yang dari saat ke saat selalu berubah dan berkembang sesuai dengan tuntutan zaman. Sesuatu yang paling dominan dalam pendidikan adalah faktor manusia yang terlibat di dalamnya menyangkut pendidik, anak didik dan tenaga kependidikan.

Oleh karena itu apabila mau melihat karakter pendidikan perspektif pendidik dan tenaga kependidikan harus melalui pendekatan historik dan hermeneutik. Melalui pendekatan historik, akan dikaji perkembangan masyakarat Banjar dari semenjak munculnya masyarakat Banjar hingga perkembangannya saat ini. Adapun melalui pendekatan hermeneutik akan dicoba diketahui makna dari berbagai artifak, simbol, nomenklatur dan perilaku pendidik dan tenaga kependidikan yang mengungkap arti dan makna serta berbagai pandangan mereka mengenai pendidikan.

Karakter pendidikan yang menjadi ciri khas esensial suatu pendidikan di lapisan masyarakat tertentu harus digali untuk dijadikan bahan renungan menatap pendidikan ke depan. Mana-mana nilai budaya yang masih perlu dipertahankan dan mana-mana nilai budaya yang perlu disesuaikan atau dimodifikasi sesuai dengan tuntutan kemodernan sekarang ini.

\section{Masyarakat Banjar dan Budayanya}

Menurut teori Prof Dr Alfani Daud, bahwa orang Banjar adalah berintikan pecahan sukubangsa Melayu yang sekitar lebih dari seribu tahun yang lalu berimigrasi secara besar-besaran ke kawasan ini, dari Sumatera atau sekitarnya. ${ }^{1}$ Masyarakat Banjar ada yang dikenal dengan masyarakat Banjar Batang Banyu dan Masyarakat Banjar Pahuluan dengan karakteristik yang sama

${ }^{1}$ Alfani Daud, Islam dan Masyarakat Banjar Diskripsi dan Analisa Kebudayaan Banjar, (Jakarta: PT RajaGrafindo Persada, 1997), h. 25. 
yakni beragama Islam dan dengan mengunakan bahasa Banjar meskipun dengan dialek yang berbeda.

Mengingat Islam sebagai ciri khas masyarakat Banjar, maka masyarakat Ngaju yang masuk Islam seperti orang-orang Ngaju di Marabahan dan sekitarnya yang telah memeluk Islam pada permulaan abad 19, mereka menjadi orang Banjar, walaupun terkenal sebagai orang Bakumpai. ${ }^{2}$

A Ghazali Usman dalam sebuah seminar menyatakan bahwa masyarakat Banjar itu terbentuk bersamaan dengan berdirinya kerajaan Islam di Bandjarmasih (sekarang Banjarmasin) pada tahun 1526. Kerajaan ini seperti diutarakan dalam Hikayat Banjar didirikan oleh Raden Samudra, pangeran mahkota yang terbuang dari kerajaan Hindu di Negaradaha dari pamannya sendiri, yaitu pangeran Tumanggung, setelah ia memperoleh bantuan pasukan sukarelawan dari kerajaan Islam Demak (Jawa). Segera setelah itu ia memindahkan pusat pemerintahan ke Banjarmasin. Raden Samudera sendiri kemudian memeluk agama Islam dan menjadikan agama ini sebagai agama kerajaan. Sejak itu ia bergelar Sultan Suriansyah. Rakyatnya yang beragama Islam baik orang-orang Melayu, Jawa maupun Dayak (Ngaju, Maanyan, Lalawangan dan Bukit) merupakan unsur-unsur utama terbentuknya masyarakat Banjar. ${ }^{3}$

Menurut H. Gt. Abdul Muis, Agama Islam masuk ke daerah Kalimantan Selatan sekitar permulaan abad ke $16 \mathrm{M}$ dibawa oleh para pedagang dan mubaligh lewat pantai utara Jawa Timur. ${ }^{4}$ Islam sebenarnya sudah mulai dianut oleh sebagian masyarakat sebelum berdirinya Kerajaan Banjar, akan tetapi setelah kerajaan Banjar berdiri, maka seluruh masyarakatnya memeluk Islam disebabkan Islam dijadikan agama resmi kerajaan, dan perkembangan agama Islam pun terjadi pesat sekali. Akan tetapi perkembangan masuk Islam tersebut tidak diimbangi dengan perkembangan pengetahuan keislaman masyarakatnya, sampai kembalinya Syekh Muhammad Arsyad al-Banjari (1710-1812) dari Mekkah setelah belajar disana selama 30 tahun.

Segera setelah tiba di kampung halamannya pada tahun 1772, Syekh Arsyad bergiat melakukan dakwah secara sistematis dan berencana. Ia berusaha mengikis unsur-unsur animisme-Hinduisme-Buddhisme dari kepercayaan dan praktik keagamaan yang sama sekali tidak sesuai dengan ajaran Islam yang

${ }^{2}$ Alfani Daud, Islam dan Masyarakat Banjar ..., h. 34.

${ }^{3}$ Analiansyah dkk., Aspirasi Pendidikan Masyarakat Banjar, (Banjarmasin: Antasari Press, 2007), h. 7-8.

${ }^{4}$ Analiansyah dkk., Aspirasi Pendidikan Masyarakat Banjar ..., h. 8. 
benar. Pada tahun 1777 Syekh Arsyad menulis kitab “Tuhfatur Raghibin” yang menyerang dengan keras sekali kepercayaan dan praktik keagamaan yang menyimpang dari ajaran Islam. Dan lima tahun kemudian ia menulis kitab "Sabilal Muhtadin", kitab fikih lengkap berdasarkan mazhab Syafi'i yang tebalnya lebih dari 500 halaman (2 jilid). Dua kitab yang disebut terakhir ditulisnya dalam bahasa Melayu yang mudah difahami oleh rakyat, atas permintaan Sultan Tahmidullah (memerintah tahun 1761-1801). Kedua kitab ini konon sangat populer di beberapa wilayah nusantara, bahkan sampai ke Semenanjung Malaka, Kamboja dan Siam. Syekh Muhammad Arsyad al-Banjari juga dikenal sebagai ulama ahli tasawuf, suluk dan khalwat, tetapi menentang faham wibdatul wujud (monoisme). Dialah yang menyarankan hukuman mati bagi Syekh Abdul Hamid yang mengajarkan faham wibdatul wujud kepada masyarakat awam. Tetapi karya tulis Syeckh Arsyad bidang tashawuf ini yang dapat diketahui cuma kitab "Kan₹ul Ma'arif”. Kitab ini rupanya kurang populer dibandingkan dengan kitab tashawuf yang dikarang oleh Syekh Muhammad Nafis al-Banjari pada tahun 1782 "Ad Durun Nafis".

Memperhatikan faham tauhid dan tashawuf yang dikembangkan serta terkenalnya kitab Sabilal Muhtadin sebagai referensi keagamaan di zamannya, bahkan hingga saat ini oleh sebagian masyarakat Banjar, maka jelas bahwa faham ahlussunnah waljamaah dan mazhab Syafi'i menjadi frame keagamaan masyarakat Banjar.

\section{Karakter Pendidikan dalam Budaya Banjar (Perspektif Pendidik dan Tenaga Kependidikan)}

Istilah pendidik dan tenaga kependidikan memang sukar dilacak di awal perkembangan masyarakat Banjar atau diawal berdirinya kerajaan Banjar (abad 16). Mereka yang berperan dalam mencerahkan dan mendidik masyarakat waktu itu lebih dikenal sebagai ulama dengan berbagai sebutan sesuai dengan tingkat keulamaannya.

Alfani Daud dengan mengutif Ras, (1968:460) menyatakan:Tidak banyak keterangan tentang jabatan-jabatan agama apa saja yang ada di kesultanan Banjar pada zaman permulaan Islam, atau tepatnya pada masa pemerintahan sultan Suriansyah dan sultan-sultan berikutnya. Hikayat Banjar menyebutkan jabatan panghulu (penghulu), chatib (khatib) dan chalifah (khalifah); adakalanya

\footnotetext{
${ }^{5}$ Analiansyah dkk., Aspirasi Pendidikan Masyarakat Banjar ..., h. 10-11.
} 
juga disebut tuan penghulu, tuan khatib dan tuan khalifah, mungkin yang dimaksudkan ialah yang sudah pergi haji. Kedudukan penghulu di bawah mangkubumi dan tugasnya ialah berkenaan dengan masalah penerapan hukum agama. ${ }^{6}$

Berkenaan dengan jabatan agama di akhir kesultanan Banjar antara lain ada jabatan mufti. Sultan dianggap sebagai kepala seluruh pejabat agama, di bawah sultan ada mufti yang kewibawaannya meliputi seluruh pejabat agama dalam wilayah kesultanan dan sebagai hakim tertinggi. Sebagai hakim tertinggi, mufti melakukan pengawasan atas seluruh pengadilan di dalam wilayah kesultanan. Sebagai hakim sehari-hari di ibukota bertindak seorang kadi; sebagai kadi pertama juga ditunjuk salah seorang keturunan Syekh. Dapat diduga, baik mufti maupun kadi mempunyai wewenang sebagai pengelola mesjid ibukota. Seorang kadi, kerena kedudukannya di ibukota mungkin mempunyai wibawa pula terhadap hakim-hakim di tingkat daerah. Pejabat agama di daerah lalawangan (daerah kira-kira setingkat kabupaten di Jawa) dinamakan penghulu, kewenangannya meliputi pula pengelolaan mesjid di ibukotanya, disamping sebagai hakim sehari-hari untuk wilayahnya dan melakukan pengawasan atas pejabat-pejabat agama di dalam wilayahnya itu. Seorang penghulu dibantu oleh khalifah yang wewenangnya mewakili penghulu dan menggantikan tugasnya apabila berhalangan (termasuk wewenang mengadili). Di tempat kedudukan lurah semacam kepala distrik yang membawahi kampung-kampung ada seorang pejabat agama yang disebut khalifah. Tugasnya mungkin sama dengan tugas penghulu, kecuali bahwa seorang khalifah tidak mempunyai wewenang mengadili apabila tidak ada pelimpahan dari penghulu. Pejabat agama pada tingkat kampung dinamakan wakil penghulu. Kewenangnanya khusus sebagai pegawai administrasi berkenanan dengan perkawinan (akad nikah secara Islam) dan perceraian bagi warga kampungnya.

Adapun ulama yang lebih dekat kepada tugas mengajar dan mendidik umat sepanjang sejarah masyarakat Banjar ada yang disebut tuan guru, guru dan fakih. Guru adalah panggilan bagi ulama yang belum menunaikan ibadah haji. Tuan Guru bilamana seorang Guru telah menunaikan haji. Adapun Fakih adalah seorang ulama yang khusus hanya menguasai ilmu fikih saja. Di beberapa tempat dikenal juga sebutan Fafakihan yakni seorang yang dianggap masyarakat lingkungannya sebagai ahli ilmu fikih, tetapi biasanya kurang

${ }^{6}$ Alfani Daud, Islam dan Masyarakat Banjar ..., h. 55.

${ }^{7}$ Alfani Daud, Islam dan Masyarakat Banjar ..., h. 56-57. 
memahami Ilmu Nahu dan Bahasa Arab. Keahliannya dalam hal fikih dipelajari dengan guru atau menelaah kitab fikih yang berbahasa Arab Melayu. ${ }^{8}$ Tuan Guru juga ada yang dikenal sebagai Tuan Guru Tuha. ${ }^{9}$ Penghormatan masyarakat terhadap ulama didasarkan kepada keluasan pengetahuan ulama tersebut.

Seorang ulama terkemuka yang datang pada suatu selamatan akan segera didekati ulama-ulama yang kurang terkemuka dan tamu-tamu lainnya guna disalami dan sebagian ada yang berusaha mencium tangannya. Seorang guru agama memperoleh penghormatan demikian pula dari murid-muridnya, seperti guru mengaji yang memperoleh penghormatan dari anak-anak yang mengaji padanya. Seorang ulama yang agak kurang terkemuka atau pembekal atau tamu lainnya yang menempati ruang sekitar tawing halat biasanya hanya menyalami tamu-tamu yang duduk disekitarnya saja, sedangkan tamu lainnya ada yang beredar menyalami tamu yang lebih dahulu hadir, khususnya yang berada di tawing halat sebelum dia menduduki tempatnya yang agak jauh dari tawing halat tersebut. Untuk membaca doa dan memimpin tahlil kehormatan diberikan kepada ulama yang paling terkemuka, atau dalam hal selamatan terbatas pada keluarga luas dan tetangga dekat, kehormatan diberikan kepada orang yang paling allim diantara yang hadir. Adakalanya seorang ulama yang diberi kehormatan untuk membaca doa, mempersilahkan kepada ulama yang kurang terkemuka untuk memimpin acara tahlil dan doa tersebut, mungkin sebagai pernyataan bahwa ulama yang terakhir inipun sudah tinggi ilmunya.

Apabila berjumpa di jalan, seorang anak muda diharapkan bertegur sapa lebih dahulu terhadap kerabatnya yang lebih tua. Menjumpai seorang ulama terkemuka di tengah jalan berarti kesempatan untuk bersalaman dengannya dan sedapat-dapatnya mencium tangannya, lebih-lebih apabila si ulama tersebut memang dikenalnya. Para pemuda yang ngobrol seringkali merasa harus menghentikan obrolan sementara si ulama lewat. ${ }^{10}$ Tidak itu saja belakangan seringkali murid-murid madrasah swasta bergotong royong mengerjakan sawah milik guru mereka. Kesadaran ini menjadi salah satu bentuk dari penghormatan kepada guru mereka.

${ }^{8}$ Lihat: Kamrani Buseri, Gagasan Tentang Pendidikan di Kalangan Orang Banjar Dan Penerapannya Pada Tiga Lembaga Pendidikan Swasta Agama (Laporan Penelitian), (Banjarmasin: IAIN Antasari, 1986), h. 27.

${ }^{9}$ Seorang ulama seperti H. Muhammad Ramli orangtua dari Tuan Guru H Mahfuz Amin disebut sebagai Tuan Guru Tuha.

${ }^{10}$ Alfani Daud, Islam dan Masyarakat Banjar ..., h. 101-102. 
Ulama di awal berdiri kerajaan Banjar berperan sebagai pejabat negara di bidang keagamaan dan diberi kewenangan penuh menangani keagamaan baik pengadilan, pernikahan, waris maupun dakwah dan pendidikan.

Pada awal kerajaan Banjar berdiri, aktivitas pendidikan belumlah tampak, baru setelah abad ke 17, berkembang pendidikan agama Islam dalam bentuk pengajian yang diasuh oleh tuan guru. Sebenarnya kegiatan pengajian merupakan bagian dari kegiatan dakwah dan pendidikan. Lembaga pendidikan belum dikenal waktu itu sehingga dakwah dan pendidikan berlangsung di mesjid dan langgar juga di rumah-rumah ulama sendiri.

Kegiatan pengajian terus berlangsung sampai dengan abad ke 19. Lembaga pendidikan Islam swasta yang tertua yang ditemukan adalah "Islamic School" yang didirikan oleh sebuah organisasi orang Arab di Banjarmasin yaitu "Musaadatul Ikhwan" yang dipimpin oleh Ibrahim al-Mualla. Mulanya berlokasi di Jalan Antasan Kecil Barat, kemudian pindah ke Kampung Bugis Jalan Sulawesi pada tahun $1903 .{ }^{11}$ Setelah itu berturut-turut antara lain 14 Juli 1914 berdiri Madrasah "Al Imad fi Ta'limil Aulad Darussalam” di Martapura; Tahun 1916 Cabang Sayarikat Islam Kandangan membikin gedung untuk perkumpulan sekaligus tempat belajar yakni pada bagian lantai dua. Kegiatan itu disebut "Islam Studi Club" atau sering disebut "Kalap". Sekolah Islam Kalap ini kemudian setelah berjalan sekitar 15 tahun dipindah ke kampung Pandai Kandangan, dan sejak itu populer dengan "Sekolah Islam Pandai". Pada tahun 1924 di Amuntai berdiri sekolah Islam yang kemudian pada tahun 1927 diberi nama "Arabische School" yang kemudian menjadi Madrasah Rasyidiyah, terakhir menjadi Ma’had Rasyidiyah. Pada tahun 1931 Musyawaratut Thalibin mendirikan beberapa madrasah antara lain di Wasah, Padang Batung dan Angkinang (Kabupaten HSS), di Alabio dan Amuntai (Kabupaten HSU); di Kelua (Kabupaten Tabalong dan untuk tingkat Tasanawiyah di Rantau dengan sebutan Normal Islam tahun 1940. Tahun 1934 berdiri Madrasah Islamiyah di Pantai Hambawang (Kabupaten HST), pada tahun yang sama banyak berdiri dan kemudian membentuk Persatuan Perguruan Islam (PPI). Tahun 1925 berdiri cabang Muhammadiyah di Alabio yang kemudian pada tahun 1928 didirikan Sekolah Dasar Muhammadiyah dengan nama Volks School. Kemudian tahun 1930 di Rantau juga berdiri sekolah Muhammadiyah. Pada tahun 1933 di Alabio (HSU) didirikan sekolah oleh golongan NU, dan pada

${ }^{11}$ Analiansyah dkk., Aspirasi Pendidikan Masyarakat Banjar ..., h. 25. 
tahun 1934, NU juga masuk ke daerah Haruyan, sejak itu PPI terbagi dua ada yang tetap dan ada yang masuk ke organisasi NU. ${ }^{12}$

Sesuai dengan perkembangan, belakangan beberapa Madrasah berubah menjadi pesentren sementara ada pula pendirian baru pesantren seperti pondok pesantren Darul Hijrah Cindai Alus Banjarbaru, Pondok Pesantren Al Falah Banjarbaru, Pondok Pesantren Istiqamah Barabai, dan lain-lain. PondokPondok Pesantren tersebut ada yang berorientasi kepada Salafi dan ada yang modern yakni menggabungkan antara kurikulum pesantren dengan kurikulum madrasah atau sekolah.

Sejalan dengan perkembangan lembaga pendidikan dimaksud term pendidik juga berkembang. Di zaman pengajian, pendidik adalah para ulama yang mumpuni dalam hal penguasaan "Kitab Kuning". Penguasaan kitab kuning salah satu karakteristik utama sebagai seorang ulama dalam masyarakat Banjar yang memiliki kewenangan besar dalam dakwah dan pendidikan, karena dengan menguasai sejumlah kitab kuning menunjukkan keahlian yang mendalam di bidang ilmu-ilmu keislaman sekaligus menunjukkan posisi keterhormatan seorang ulama dimaksud. ${ }^{13}$ Tentu saja selain penguasaan kitab kuning, sorang ulama sangat berwibawa karena menunjukkan integritas pribadinya sebagai pendidik dan juru dakwah yang selalu konsisten dalam mengamalkan ajaran agama dalam kehidupan sehari-hari di tengah-tengah masyarakat. Mereka menjadi tempat rujukan bagi teladan masyarakat dalam berbagai hal menyangkut siklus kehidupan mulai perkawinan, kelahiran hingga kematian.

Dalam perkembangannya ada pengajian khusus, maka ada ulama yang hanya menguasai fikih disebut Fakih dan menguasai fikih untuk amalan seharihari seperti yang termuat dalam "Perukunan Besar" disebut Fafakihan. Semuanya memiliki tempat tersendiri sebagai pendidik di lingkungan masyarakat tertentu.

Sejalan dengan berdirinya madrasah, maka term pendidik juga berkembang yakni ada pendidik formal yang disebut ustazt pada pesantren/madrasah dan guru pada madrasah. Penguasaan kitab kuning bagi ustazt dan ustaztah khususnya yang mengajar di pesantren tetap menjadi persyaratan, sementara bagi pendidik yang mengajar di madrasah (Ibtidaiyah,

\footnotetext{
${ }^{12}$ Lihat uraian lengkap pada Analiansyah dkk., Aspirasi Pendidikan Masyarakat Banjar ..., h. $26-33$.

${ }^{13}$ Sejumlah ulama memiliki karya sesuai keahliannya, ada karya mereka berkenaan dengan bidang tauhid, bdang fikih dan bidang tasawuf. Uraian lengkap lihat: Bayani Dahlan (Editor), Ulama Banjar \& Karya-Karyanya, (Banjarmasin: Antasari Press, 2009).
} 
Tsanawiyah dan Aliyah) tidak begitu dipersoalakan karena lebih menekankan ijazah formal sebagai kualifikasi karena telah menyelesaikan studi di perguruan tinggi. Lebih-lebih setelah keluarnya undang-undang nomor 14/2005 tentang Guru dan Dosen.

Akan tetapi pada pengajian-pengajian di mesjid dan langgar masyarakat masih mengharapkan agar guru yang mengajarkan ilmu-ilmu keislaman harus menguasai kitab kuning, khususnya berkenaan dengan pendalaman ilmu fikih.

Di era kebangkitan nasional banyak para ulama ikut ambil bagian dalam politik, seperti yang terungkap dalam hasil penelitian14, sebut saja antara lain:

1. Tuan Guru H Akhmad Abdul Hamid (1903-1967) pendiri Madrasah Irtiqaiyah di Pemurus (1930) adalah dikenal sebagai tokoh Masyumi, dan pernah ditangkap Belanda tahun 1944.

2. Tuan Guru H Hanfi Gobit (1914-1990) pencetus berdirinya SMIP (1946), sekaligus salah seorang pendiri IAIN Antasari (1964), pernah menjadi Dewan Banjar (1948-1950), anggota konstituante (1955-1959), menjadi anggota MPR (1977-1982).

3. Tuan Guru H Jamaluddin pendiri Madrasah Darussalam Martapura (1914), pendiri sekaligus Ketua Partai Syarikat Islam Kalimantan Selatan.

4. Tuan Guru Syekh Abdul Kadir Hasan, pendiri NU (1928) dan pernah menjadi angota DPRGR Tk I Provinsi Kalimantan Selatan (1966-1972).

5. Tuan Guru H Zafry Zamzam (1908-1972). Tahun 1931 aktif di Persatuan Bangsa Indonesia (PBI), selanjutnya di Partai Islam Indonesia (PII) pernah menjadi anggota KNIP wakil Kalimantan, anggota DPRD (1950) dan menjadi anggota MPRS mewakili golongan fungsional ulama.

6. Tuan Guru H Kasyful Anwar lahir tahun 1920 di Sungai Paring Kandangan. Aktivis Serikat Muslim Indonesia (SERMI) berlanjut aktif di Masyumi. Beliau pernah duduk sebagai anggopta DPRDS bahkan sebagai Ketua, kemudian tahun 1958-1964 menjabat sebagai Bupati HSS.

7. Tuan Guru Haji Mansur Islamil (1905-1983) seorang ulama di HST, menjadi aktivis partai Parindra di bawah pimpinan pusat Abd Kahar Mazakkir, Pengurus harian partai SERMI cabang Barabai dan pernah menjadi anggota DPR.

\section{Membangun Karakter Pendidikan}

${ }^{14}$ Lihat: Tim Peneliti Fakultas Tarbiyah Banjarmasin, Elite Muslim di Kalimantan Selatan (Studi Gerakan Elite Muslim di Bidang Pendidikan 1900-1950), (Banjarmasin: Institut Agama Islam Negeri, Fakultas Tarbiyah Banjarmasin, 1993), h. 15-60. 


\section{Internalisasi Nilai Positif}

Bilamana dianalisis dari perkembangan pendidikan dalam kontek budaya Banjar dalam perspektif pendidik, maka memelihara nilai-nilai lama yang positif dan mengambil nilai-nilai baru yang lebih positif selalu terpelihara dan diteruskan dari generasi ke generasi, mengingat pendidikan adalah upaya memanusiakan manusia agar menjadi manusia yang mampu beradaptasi dengan situasi di zamannya. Hal tersebut sejalan dengan latar belakang ulama-ulama yang bergerak di bidang pendidikan kebanyakan berlatar belakang pendidikan luar negeri (Mekkah dan Mesir) dan hanya sedikit yang mengecap pendidikan di dalam negeri. Adapun yang terakhir antara lain pernah belajar di pondok pesantren Al-Ashriah Banjarmasin, Darussalam Martapura, Gontor Ponorogo dan Normal Islam Padang. ${ }^{15}$

Dari gambaran di atas sekaligus menunjukkan bahwa salah satu karakter pendidikan masyarakat Banjar sangat menghargai kualitas, baik kualitas pendidik, kualitas proses maupun kualitas produk.

Faham ahlussunnah waljamaah merupakan karakteristik pendidikan yang penting dan akan dapat menjadi barer sekaligus tolok ukur terhadap berkembangnya dua ekstrim faham keagamaan yang sedang muncul saat ini yakni faham ekstrim liberal-pluralisme dan ekstrim fondamentalisme.

Salah satu yang penting dicatat adalah karakteristik ulama yang menguasai kitab kuning sebagai modal utama bagi pendidik khusus ilmu-ilmu keislaman (tafaqqub fi addin) merupakan kaharusan yang harus diabadikan hingga kapanpun.

Seorang ulama sebagai pendidik yang memiliki integritas kepribadian merupakan keharusan yang tidak boleh lenyap dari seorang pendidik. Seorang pendidik yang tidak memiliki kepribadian yang utuh tidak akan mungkin memiliki gezag yang merupakan salah satu syarat penting dalam menjalankan tugasnya sebagai pendidik, baik pendidik di keluarga, masyarakat ataupun pendidik di lembaga pendidikan formal.

Pendidik yang memiliki integritas kepribadian itulah yang mampu mempertahankan kualitas/mutu yang akan mampu melahirkan anak didik yang mandiri dan kompetitif.

${ }^{15}$ Hasil penelitian Tim Peneliti Fakultas Tarbiyah IAIN Antasari, Elite Muslim di Kalimantan Selatan (Studi Gerakan Elite Muslim di Bidang Pendidikan 1900-1950), dari 21 responden, 17 responden berpendidikan luar negeri, 4 responden saja yang hanya mengecap pendidikan di dalam negeri, 1993, h. 64. 
Disebabkan pendidik/guru memiliki integritas keperibadian, maka mereka sangat dihormati oleh murid-muridnya. Para muridnya sangat takut melakukan perbuatan yang tidak terpuji di hadapan guru bahkan tidak dihadapan gurunya sekalipun karena khawatir diketahui oleh gurunya. Di awalawal perkembangan pengajian, guru seringkali diyakini memiliki indra ke enam sehingga diyakini mengetahui perilaku murid-muridnya meskipun beliau tidak melihat langsung.

Pada tahun-tahun awal berdirinya madrasah-madrasah, nilai kebersamaan, saling membantu dan persatuan antar madrasah sangat menonjol, seperti berdirinya Persatuan Perguruan Islam (PPI) di Barabai (1937) dan Persatuan Madrasah Amandit yang diketuai oleh Tuan Guru H.M. Arsyad. ${ }^{16}$

\section{Transpormasi Nilai}

Sejalan dengan perubahan paradigma dalam pendidikan yakni dengan memandang ilmu secara lebih luas terutama setelah berkembangnya sistem madrasah dan persekolahan, maka term pendidik juga berubah misalnya muncul istilah ustazt, ustaztah dan guru. Ustazt/ustaztah yang masih berkonotasi dengan ulama, maka karakteristik penguasaan kitab kuning mutlak dikuasai. Berbeda dangan guru yang lebih dipandang sebagai orang yang menggantikan kedua orangtuanya mendidik anaknya di sebuah lembaga pendidikan.

Para pendidik mempengaruhi pandangan aspirasi masyarakat. Aspirasi umum masyarakat Banjar agar anak-anak mereka mengenyam pendidikan agama "sekedar cukup" untuk bekal kebahagian di dunia dan di akhirat. Sedangkan aspirasi khusus agar anak didik diharapkan menjadi ulama. Dilain pihak bila dilihat perkembangan lembaga pendidikan, maka tampak berbagai kategori, seperti:

1. Bertahan pada pola tradisional

2. Menerapkan gagasan modern

3. Penyesuaian bertahap dari tradisional ke modern

4. Ada yang menoleh ke belakang, dari modern kembali ke tradisional. ${ }^{17}$

\section{Penutup}

\footnotetext{
${ }^{16}$ Lihat: Tim Peneliti Fakultas Tarbiyah Banjarmasin IAIN Antasari, Elite Muslim di Kalimantan Selatan ..., h. 33 dan 42.

${ }^{17}$ Lihat: Analiansyah dkk., Aspirasi Pendidikan Masyarakat Banjar ..., h. 101 dan 103.
} 
Para ulama, tuan guru, guru, ustaz dan lainnya berperan dalam mengembangkan pola pendidikan sepanjang sejarah masyarakat Banjar. Bangunan karakteristik pendidikan yang terus menerus selalu ada sepanjang sejarah ialah pendidikan keislaman, mengingat Islam merupakan identitas masyarakat Banjar. Penyesuaian dengan tuntutan keadaan selalu menjadi kebijakan pendidikan masyarakat Banjar. Hal tersebut diperkuat oleh banyaknya ulama yang berlatar belakang pendidikan luar negeri yang sangat mempengaruhi modernitas pendidikan di masyarakat Banjar.

Karakter ulama (pendidik) harus menguasai Kitab Kuning dan memiliki integritas kepribadian yang memunculkan gezag sehingga memperoleh penghormatan yang tinggi di masyarakat.

Sesuai sejarah perkembangan awal masyarakat Banjar, ulama sebagai pendidik sekaligus sebagai juru dakwah merupakan kompetensi ganda bagi pendidik yang seharusnya menjadi karakter pendidik hingga saat ini. Lembaga pendidikan selain misi mendidik juga misi dakwah. Pada situasi tertentu pendidik juga dibenarkan terjun ke dunia politik dengan tujuan utama memperkuat pendidikan masyarakat dan bangsa.

Internalisasi nilai-nilai positif, faham ahlussunnah wal jamaah, keahlian kitab kuning, menghargai kualitas, integritas kepribadian, nilai kebersamaan, persaudaraan dan persatuan adalah modal dalam membangun karakter pendidikan masyarakat Banjar. Begitupula transpormasi nilai berlangsung sejalan dengan tuntutan zaman sehingga memunculkan term pendidik yang variatif seperti Guru, Tuan Guru, Tuan Guru Tuha, ustaz dan guru secara umum, begitupla tenaga kependidikan yang muncul belakangan memiliki term yang variatif ada murabbi, ketua yayasan.

\section{Daftar Pustaka}

Daud, Alfani, Islam \& Masyarakat Banjar: Diskripsi dan Analisis Kebudayaan Banjar, Jakarta, PT. RajaGrafindo Persada, 1997.

Analiansyah, dkk., Aspirasi Pendidikan Masyarakat Banjar, Banjarmasin, Antasari Press, 2007.

Dahlan, Bayani (Editor), Ulama Banjar \& Karya-Karyanya, Banjarmasin, Antasari Press 2009. 
Buseri, Kamrani, Gagasan Tentang Pendidikan di Kalangan Orang Banjar Dan Penerapannya Pada Tiga Lembaga Pendidikan Swasta Agama (Laporan Penelitian), Banjarmasin, IAIN Antasari, 1986.

Tim Peneliti Fakultas Tarbiyah Banjarmasin, Elite Muslim di Kalimantan Selatan(Studi Gerakan Elite Muslim di Bidang Pendidikan 1900-1950), Banjarmasin, Institut Agama Islam Negeri, Fakultas Tarbiyah Banjarmasin, 1993. 
